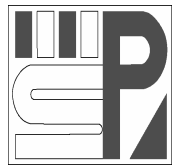

Science Press
Journal of Arid Land

2012, 4(1): 95-104

doi: 10.3724/SP.J.1227.2012.00095

jal.xjegi.com; www.chinasciencejournal.com

\title{
Ecological migration effects on the Tianchi Scenic Area in Xinjiang: from the perspective of migrant farmer families
}

\author{
Hong TANG ${ }^{1,2}$, DeGang YANG ${ }^{1 *}$, XinHuan ZHANG $^{1}$, XinYi XIANG ${ }^{3,4}$ \\ ${ }^{1}$ Xinjiang Institute of Ecology and Geography, Chinese Academy of Sciences, Urumqi 830011, China; \\ ${ }^{2}$ Graduate University of Chinese Academy of Sciences, Beijing 100049, China; \\ ${ }^{3}$ School of Geographical Sciences, Southwest University, Chongqing 400715, China; \\ ${ }^{4}$ Central Division of Analytical Chemistry (ZCH), Forschungszentrum Jülich $\mathrm{GmbH}$, Jülich 52425, Germany
}

\begin{abstract}
As an important approach for relieving conflicts between ecosystems and human activities in the Tianchi Scenic Area, Xinjiang of China, an ecological migration policy was implemented, aiming to improve the regional ecological environment. The case of resettlement was closely related to the smooth implementation of the migration project. Based on the questionnaires and farmer family interviews, both changes in the ecological environment and the living conditions of migrant farmer families in the Tianchi Scenic Area were investigated in this study. The objectives were to assess the benefits of the ecological migration policy and to analyze the effects of ecological migration on migrant farmer families. The results showed that (1) awareness of the need for ecological environmental protection and the types of migrant families had a great influence on the willingness to migration; (2) since the implementation of the ecological migration project, the ecological environment in the Tianchi Scenic Area had improved significantly, particularly in terms of returning farmland to forestry, while pressures on grassland had also been relieved to some extent; (3) the major income sources and occupations of the migrant farmer families changed, the range of their income sources declined, and their per capita incomes decreased at different degrees; and (4) nearly half of the farmer families were not satisfied with the living environment of new settlements and the decline in the quality of life had significant influences on the attitudes of migrants. In order to ensure the successful implementation of an ecological migration project, it is essential to enhance farmer awareness of needs for ecological environmental protection, and to solve resettlement problems properly.
\end{abstract}

Keywords: ecological migration; migration project; migrant farmer families; questionnaire; Tianchi Scenic Area; Xinjiang

Influenced by global climate change and human activities, most regions of China show the evidence of soil erosion and land degradation, and most grasslands are under varying degrees of degradation ( $\mathrm{Lu}$ and Zhao, 2009), which may result in serious threats on the ecological environment and the living of farmers and herders. An ecological migration policy has become an important method to protect and restore the ecological environment, which is believed to be able to alleviate the conflict between ecological pressure and the needs of human survival (Zhang, 2005). There are nearly $200 \mathrm{hm}^{2}$ of grasslands in the Tianchi Scenic Area of the Tianshan Mountains in Xinjiang, which were once mostly used as summer pasture by herders of the Sangong River valley in Fukang city (Ren and Lan, 2008). With the development of tourism and livestock raising, the conflict between different uses of grassland became more and more severe. In addition, serious grassland degradation and soil erosion threats were present. Ecological migration and pastoral settlement policies have been implemented since 2003 in order to protect and improve the ecological environment. A large number of farmers and herders in the Sangong Valley have gradually moved to Baisihumu,

Received 2011-04-13; accepted 2011-10-01

*Corresponding author: DeGang YANG (E-mail: dgyang@ms.xjb.ac.cn) 
Xitaizi and other settlements. Some studies have dealt with the ecological migration project from different aspects, analyzing its drivers and ecological and economic effects (Gai et al., 2005; Zhu and Zhang, 2006; Meng et al., 2008). Effects of ecological migration on farmers' production and life style and the ecological environment have also received extensive attention (Xu, 2001; Li, 2007; Liu and Wang, 2010). However, few studies emphasized the effects of the implementation of ecological migration on the migrant farmers themselves. In fact, the research on changes in farmers' production and living, income, and ecological environment before and after eco-migration is important for evaluating ecological migration project.

Important questions seem to be: (1) What are the attitudes of the farmers toward migration? (2) Can the ecological environment be improved after the implementation of a migration project? and (3) Can the migrants settle down properly? Aiming to find answers to these questions, a questionnaire based on Goujard et al. (2005) and Xu et al. (2007) was used to interview migrant farmer families in the settlement of Baisihumu, Fukang city, similar to the surveys of Xu et al. (2007), Ye et al. (2007), Hong et al. (2008), and Lu and Zhao (2009). Understanding and evaluating the impacts of the ecological migration project in the Tianchi Scenic Area on the ecological environment and the production and lifestyle of farmers is essential for us to evaluate the ecological migration project impartially.

\section{Study area and methods}

\subsection{Study area}

The Tianchi Scenic Area is located in the middle part of the eastern Tianshan Mountains, the southern edge of Junggar Basin, which belongs to Fukang city of Changji Hui autonomous prefecture. There are six rural villages and above 1,100 farmer families in Sangong township and Shuimogou township of this area. The Baisihumu settlement, a typical area of irrigated desert oasis agriculture, sits at the junction of the Sangong River oasis and the Gurbantunggut Desert, dominated with arid climate and little precipitation. (Fig. 1). There are a total of 229 farmer families in the settlement. All residents moved in from the Tianchi Scenic Area after 2005.

\subsection{Survey method}

The Baisihumu settlement is comparatively far away from the Tianchi Scenic Area with quite different natural conditions. As a result, the migrants had to change their production and life style in the settlement The questionnaire was designed to identify such items as basic information, migration date and willingness, production and life style before and after migration, changes in incomes and ecological environment after migration. The questionnaire was conducted with all these migrant farmer families in June 2009. Considering most of the investigated farmer families were $\mathrm{Ka}$ zakh, the questionnaire was designed in Kazakh language. Both interviews and questionnaires were utilized to assure universality, objectivity and completion of the survey. The total number of questionnaires was 200 and the effective recovered number was 196. The rate of effective recovery was $98 \%$.

\subsection{Basic information about the interviews and questionnaires}

Basic information covered the age and educational background of the householders, the numbers of family members and income earners in the family (Fig. 2).

The ages of the householders fell within a normal distribution, with ages from 40 to 50 making up the largest group, which was $26.53 \%$. Householders who are older than 60 years make up the smallest part, which was only $12.24 \%$. This is almost the same as the general situation in China, householders of the age from 30 to 60 being the major part. Significant differences existed in the educational background of householders. The majority of householders (46.94\%) had only elementary education. The higher the educational level, the lower the percentage of householders became, with only $4.08 \%$ of householders having an educational level higher than junior college. And $4.08 \%$ of householders had an education level lower than elementary school. This situation mirrors the educational level of the minority groups in Xinjiang, that is, however, fewer individuals from minority groups receive higher education. Most of the minority groups have received elementary level education, which decreases the illiteracy rate significantly. 

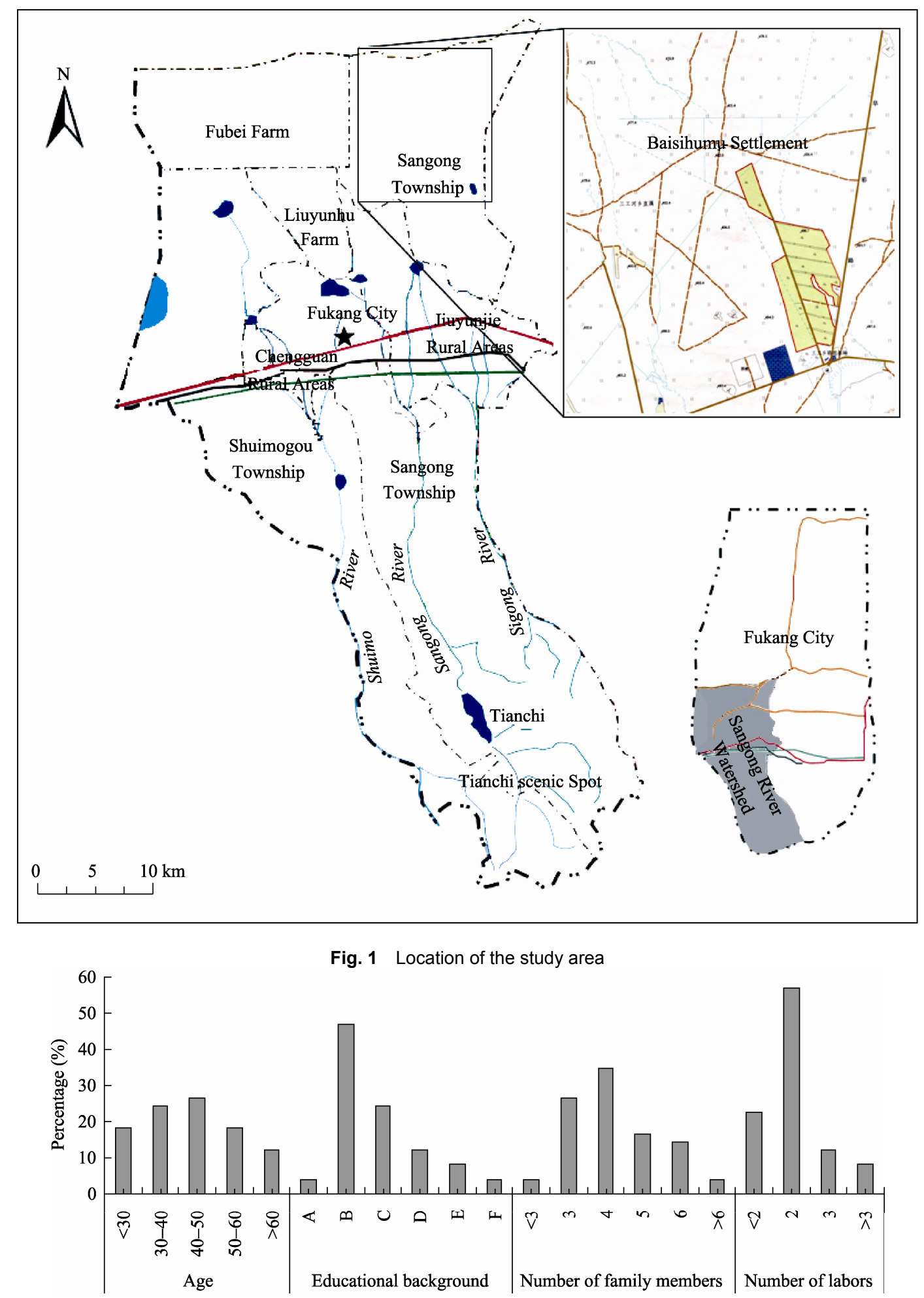

Fig. 2 Basic information about the investigated householders. A, Below elementary school education; B, Elementary school education; C, Middle school education; D, High school education; E, Post secondary vocational education; F, Junior college education and above.

Most interviewed families (34.69\%) were made up with four members, and $57.14 \%$ had two income earners. This coincides with the general condition of this region. Two children are permissible for each minority family under the population policy in Xinjiang. Thus four-member families are the commonest form. 


\section{Results and discussion}

\subsection{Attitudes toward migration and changes of income sources}

Based on the statistical data of the Baisihumu settlement, among the 229 migrant farmer families, $25 \mathrm{mi}-$ grated in 2005, 47 in 2006, 54 in 2007, 76 in 2008 and 27 in 2009. As for the 196 farmer families interviewed, the distribution of their migration dates almost coincides with the general situation in the settlement (Fig. 3 ). In the beginning, farmer families migrated willingly with mobilization from the government, but the number of migrant families was comparatively small. The number of migrant families increased, and reached its maximum in 2008. Because only migrant families in the first half of 2009 were included, the number was incomplete.

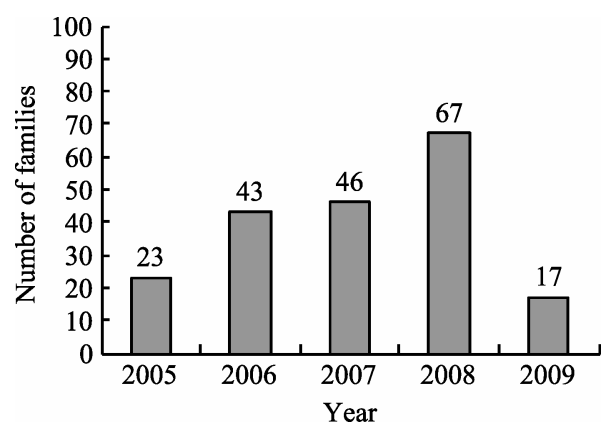

Fig. 3 Number of migration farmer families

2.1.1 Types of farmer families interviewed and their opinions towards migration

The opinion toward migration differed between fami- lies (Tang et al., 2011). The attitudes of different families toward migration were analyzed alongside various factors such as age, educational background, number of family members, major income sources, and percentage of non-agricultural incomes. The results were divided into two categories, namely, those who migrated voluntarily and those who migrated involuntarily. The data were directly obtained from the recovered questionnaires.

Among the 196 farmer families being interviewed, 84 (or $42.86 \%$ ) were willing to migrate (Table 1). Householders' age and educational background had little effect on the attitude towards migration, while the number of family members, major income sources and percentage of non-agricultural incomes had an influence on their attitudes towards migration.

Migrant families with different number of members differed in their willingness to migrate. With the increase in the number of family members, the percentage of those who were willing to migrate voluntarily decreased. The more the members of the family, the heavier the family's burden, and thus, the longer the time needed to get them acclimatized to the new environment. Migrant families with three or less members and with 4-6 members had no significant difference in their willingness to migrate. The percentages of voluntary migration for the two kinds of families were $46.67 \%$ and $43.75 \%$, respectively. Families with more than 6 members had comparatively more difficult choices to make living, and commonly had larger

Table 1 Willingness to ecological migration and types of families

\begin{tabular}{|c|c|c|c|}
\hline Index & Type & Number of families & Migration volunteers (\%) \\
\hline \multirow{4}{*}{ Age of householders (Year) } & $<30$ & 36 & 66.67 \\
\hline & $30-45$ & 72 & 33.33 \\
\hline & $46-60$ & 68 & 41.18 \\
\hline & $>60$ & 20 & 40.00 \\
\hline \multirow{4}{*}{ Educational background of householders } & Elementary school and below & 100 & 36.00 \\
\hline & Middle school & 48 & 50.00 \\
\hline & High school & 24 & 33.33 \\
\hline & Post secondary vocational school and above & 24 & 66.67 \\
\hline \multirow{3}{*}{ Number of family members } & $<4$ & 60 & 46.67 \\
\hline & $4-6$ & 128 & 43.75 \\
\hline & $>6$ & 8 & 0.00 \\
\hline \multirow{3}{*}{ Major income sources } & Farming and livestock raising & 156 & 35.90 \\
\hline & Business and tourism & 20 & 100.00 \\
\hline & Part-time jobs & 20 & 40.00 \\
\hline \multirow{3}{*}{ Percentage of non-agricultural incomes (\%) } & 0 & 76 & 52.63 \\
\hline & $0-50$ & 80 & 20.00 \\
\hline & $>50$ & 40 & 70.00 \\
\hline Total & & 196 & 42.86 \\
\hline
\end{tabular}


farmland and grassland areas than smaller families. Thus it was difficult for them to change their original lifestyles, and they migrated involuntarily.

Most families with farming, livestock raising and part-time jobs as their major sources of income were involuntary migrants, which was almost the same with the general situation. Percentage of such families migrating voluntarily was only $35.9 \%$ and $40 \%$, respectively (Table 1). The migration project had significant impact on the production and lifestyle of families whose major income source was farming or livestock raising, especially the latter, because the new settlement was far away from grassland, leading to obvious reduction in their income, and thus they were unwilling to migrate voluntarily. Families involved in business and tourism as their major income sources had seldom been affected by the settlement position and access to land, and consequently, most of these families migrated voluntarily. The percentage of nonagricultural incomes was also an important factor in the willingness to migration. For migrant families with zero, $0-50 \%$ and above $50 \%$ of non-agricultural incomes, the percentages of voluntary migration were $52.63 \%, 20 \%$ and $70 \%$, respectively.

Awareness of the need for environmental protection was another factor in the attitudes of migrant families toward ecological migration. Those families with positive environmental awareness were more willing to accept the ecological migration policy. Participation of farmer families in the project of returning farmland to forestry might have increased their awareness of the need for environment protection, and thus indirectly affected their willingness to migration for ecological reasons. An investigation was conducted on the attitudes of farmer families towards the project of returning farmland to forestry. Most of the householders had an educational background of primary school education and above, and many of them had experiences of doing business and providing tourist services, so they were conscious of the importance of environmental protection and actively participated in returning farm- land to forestry. Based on the investigation results, the percentage of migrant families participating in the project of returning farmland to forestry before migration was $38.78 \%$ and the percentage of families that migrated voluntarily was $42.86 \%$ (Table 2). Further analysis revealed 53 of the 76 families participating in the project before migration migrated voluntarily, with a percentage of as high as $69.74 \%$. Only 31 of the 120 families not participating in the project before migration were voluntary migrants, with a percentage of $25.83 \%$. From the analysis, it was concluded that awareness of the need for environmental protection had a significant impact on the attitudes towards migration.

\subsubsection{Changes of income sources}

The implementation of the ecological migration project had an obvious impact on major income sources and occupations of farmer families. Farming and livestock raising were the most important income sources before and after the implementation of ecological migration project, with the percentage of increasing from $79.59 \%$ to $85.71 \%$ after ecological migration. The percentages of families with tourism and part-time jobs as their major income sources decreased from $10.20 \%$ to $8.16 \%$ and then to $6.12 \%$, respectively after ecological migration (Fig. 4).

Statistical analysis on the occupations of farmer families showed most of the families lived mainly on farming and livestock raising before and after the implementation of the ecological migration project. In the new settlement, farmlands were allocated by the government and some herder families began to make a living by farming after migration. Consequently, the percentage of families relying on farming increased slightly. Access to grassland from settlement had increased and the convenience of grazing had decreased. The percentage of families with livestock raising as their income source decreased from $93.75 \%$ to $83.67 \%$ after migration. Before migration, $39.58 \%$ of families in the Tianchi Scenic Area participated in tourism. Af-

Table 2 Willingness to ecological migration and returning farmland to forestry

\begin{tabular}{|c|c|c|c|c|c|c|c|c|}
\hline & \multicolumn{2}{|c|}{ Participating in the project } & \multicolumn{2}{|c|}{ Voluntary to migrate } & \multicolumn{2}{|c|}{ Participating in the project } & \multicolumn{2}{|c|}{ Not participating in the project } \\
\hline & Yes & No & Yes & No & $\begin{array}{c}\text { Voluntary to } \\
\text { migrate }\end{array}$ & $\begin{array}{c}\text { Involuntary to } \\
\text { migrate }\end{array}$ & $\begin{array}{c}\text { Voluntary to } \\
\text { migrate }\end{array}$ & $\begin{array}{c}\text { Involuntary to } \\
\text { migrate }\end{array}$ \\
\hline Number of families & 76 & 120 & 84 & 112 & 53 & 23 & 31 & 89 \\
\hline Percentage (\%) & 38.78 & 61.22 & 42.86 & 57.14 & 69.74 & 30.26 & 25.83 & 74.17 \\
\hline
\end{tabular}




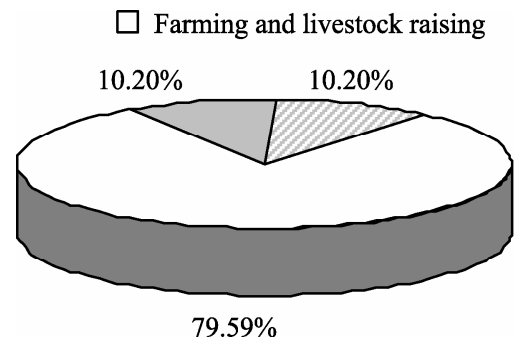

(a) Before migration (2004)

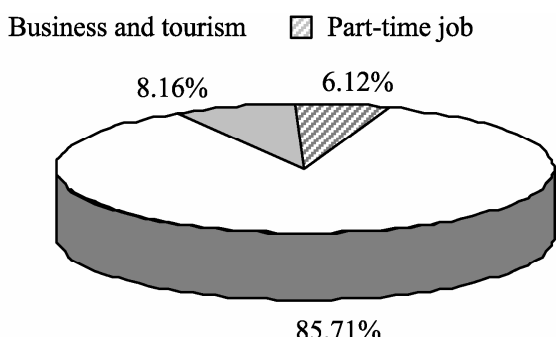

(b) After migration (2009)

Fig. 4 Changes in major income sources for migrant families before and after ecological migration

ter migration, the percentage decreased to $4.08 \%$ because of the increase in both distance and inconvenience. Similarly, the families participating in business, part-time jobs and gathering herbs decreased (Fig. 5).

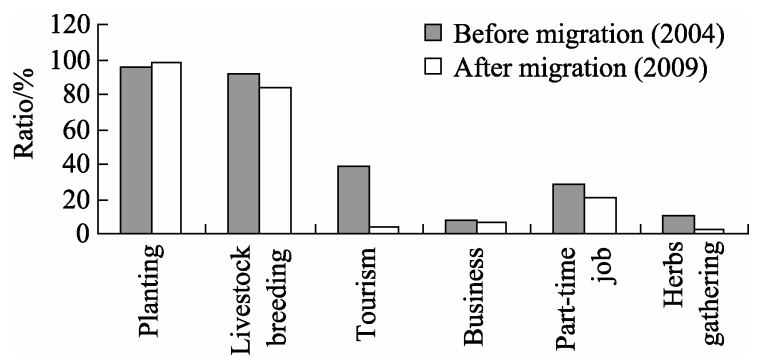

Fig. 5 Changes of occupational structure before and after ecological migration

\subsection{Ecological migration effects from the perspec- tive of migrant families}

The aims of ecological migration are to relieve the pressure on the ecological environment brought about by human activities and to improve the quality of the ecology and environment in specific regions. The relocation of migrants has an obvious impact on the implementation of a migration project. In this section, in order to evaluate the effect of migration, the results of the investigation are presented from the viewpoint of migrant families themselves to assess the changes in the ecological environment of the Tianchi Scenic Area and their new living conditions.

2.2.1 Changes in the ecological environment of the Tianchi Scenic Area

In the new settlement, farmlands were allocated by the government. In the Sangong River valley, farmlands were returned to the management board of the Tianchi Scenic Area, on a voluntary basis to return farmland to forestry. Subsidies were provided by the government to those farmer families. Of the 196 farmer-herder families being investigated, 191 had their own farm- lands, the total area of which was $54.48 \mathrm{hm}^{2}$. Before migration, 188 families participated in faming, and the total farming area was $49.52 \mathrm{hm}^{2}$, the area of farmlands returned to forestry being $4.96 \mathrm{hm}^{2}$. After migration, only $7.73 \mathrm{hm}^{2}$ held by 32 families were used for farming, and 156 families returned their farmlands to the management board. The area of returned farmlands was $46.75 \mathrm{hm}^{2}$, accounting for $85.81 \%$ of the entire farmland area (Table 3). Thus the project for returning farmland to forestry was successful.

After migration, grassland was also managed by the herders themselves. However, because the new settlement was comparatively far away from the grassland, it became inconvenient for grazing. Though livestock raising was still an income source after migration, the quantity and raising style of livestock changed. Among the investigated farmer-herder families, 184 obtained their grassland use licenses from the government and the total area of grassland was $14,914.93 \mathrm{hm}^{2}$. Before migration, 180 families used $14,652.27 \mathrm{hm}^{2}$ of grassland for grazing. After migration, 132 families used $11,949.6 \mathrm{hm}^{2}$ of grassland for the same purpose, with the utilization rate of grassland decreasing from $98.24 \%$ to $80.12 \%$ (Table 3 ). Both the number of livestock and the grazing percentage decreased significantly for the herder families continuing their livestock raising. Pressure on grassland caused by overgrazing was relieved. In this research, the number of livestock grazing on the grassland was converted into a stocking rate on the grassland before and after migration. Based on the suitable stocking number designated when allocating the grasslands, overgrazing rates were obtained (Table 4 ). The results showed that among the 132 herding families with livestock raising as their main source of income before and after migration, 61 families had their grassland overgrazed before migration, with 16 families' stoc-king numbers being more than twice the suitable quan- 
Table 3 Changes of land use in Tianchi Scenic Area before and after ecological migration

\begin{tabular}{lcccccrrr}
\hline & \multicolumn{3}{c}{ Farmland } & \multicolumn{2}{c}{ Grassland } \\
\cline { 2 - 8 } & \multicolumn{2}{c}{ Before migration } & \multicolumn{2}{c}{ After migration } & \multicolumn{2}{c}{ Before migration } & \multicolumn{2}{c}{ After migration } \\
& Farming & Returned & Farming & Returned & Gazing & Unused & Gazing & Unused \\
\hline Number of families & 188 & 3 & 32 & 159 & 180 & 4 & 132 \\
Percentage (\%) & 98.43 & 1.57 & 16.75 & 83.25 & 97.83 & 2.17 & 71.74 & 28.26 \\
Area $\left(\right.$ hm $\left.^{2}\right)$ & 49.52 & 4.96 & 7.73 & 46.75 & $14,652.27$ & 262.66 & $11,949.60$ & $2,965.33$ \\
Percentage (\%) & 90.90 & 9.10 & 14.19 & 85.81 & 98.24 & 1.76 & 80.12 \\
\hline
\end{tabular}

Table 4 Changes of overgrazing rates before and after ecological migration

\begin{tabular}{|c|c|c|c|c|c|c|}
\hline & & \multicolumn{5}{|c|}{ Overgrazing rate of grassland } \\
\hline & & $<0 \%$ & $0-20 \%$ & $20-50 \%$ & $50-100 \%$ & $>100 \%$ \\
\hline \multirow{2}{*}{ Before migration } & Number of families & 71 & 23 & 17 & 5 & 16 \\
\hline & Percentage (\%) & 53.79 & 17.42 & 12.88 & 3.79 & 12.12 \\
\hline \multirow{2}{*}{ After migration } & Number of families & 93 & 15 & 9 & 8 & 7 \\
\hline & Percentage (\%) & 70.45 & 11.36 & 6.82 & 6.06 & 5.30 \\
\hline
\end{tabular}

tity. After migration, 39 families had their grassland overgrazed, and only 7 families' stocking numbers being more than twice the suitable quantity.

Changes in climatic conditions and excessive exploitation of grassland resources caused serious land degradation, desertification and salinization in the Tianchi grassland. As a result, both the productivity and available area of grassland decreased. Based on the grassland productivity data over the last 10 years, 95\% of the grassland in the Tianchi Scenic Area suffered degradation, and both the production and the quality of grass decreased (Livestock Bureau of Fukang City, 2010). Our investigation on the herder families' perception regarding grass quality revealed that the percentage of families believing the grass quality was excellent decreased from $22.22 \%$ to $12.20 \%$ after migration, and the percentage of families believing the grass quality declined increased from $11.11 \%$ to $24.39 \%$ after migration (Fig. 6). This is similar to the grassland quality result obtained from production capacity measurements. A decrease in the number of livestock could lead to an improvement in grassland condition. In conclusion, since the implementation of the ecological migration policy, grassland degradation in the Tianchi Scenic Area has been relieved to some extent. Both overgrazing and pressure on grassland were decreased.

2.2.2 Changes in farmer families incomes and living conditions

Changes in the income and living and production conditions of migrant farmer families were important factors in the evaluation of ecological migration effects. If migrants could not be settled down properly, it

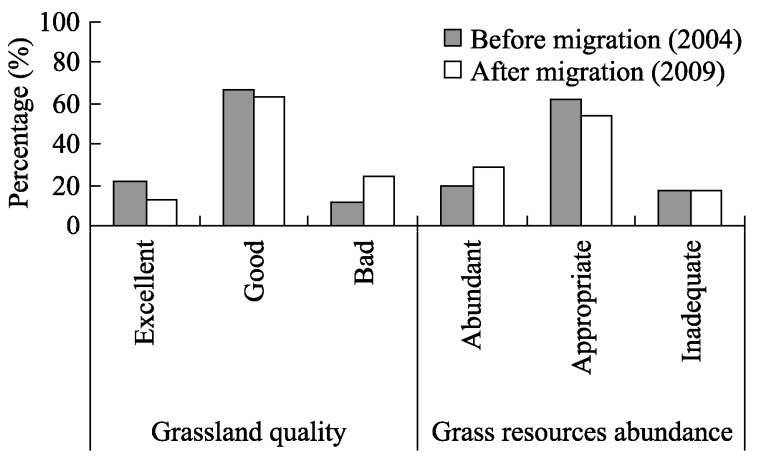

Fig. 6 Evaluation on grassland quality and grass resources abundance

would be difficult to launch the migration project. There might even be evidence of back-migration.

Changes in major income sources and occupations would lead to changes in family incomes. Before migration, farmer families lived quite close to the Tianchi Scenic Area. Besides farming and grazing, they also participated in tourism, business and other part-time jobs, with quite steady income sources. After migration, the new settlement was quite far from grassland and the Tianchi Scenic Area, which increased the cost for participating in grazing and tourism. Most migrant families made their living from farming and livestock raising, and their income sources were reduced. Most of their farmlands in the Sangong River valley were returned to the management board, but the quality of the farmland in the new settlement was inferior. The soil was seriously salinized and the irrigation system was not complete. In addition, herder families possessed poor cultivation skills. All these factors decreased their income significantly. The results showed that the income of 
$59.18 \%$ of the investigated families decreased and that of $32.65 \%$ increased (Fig. 7). Further analysis indicated that most of the families with increased income were earlier migrants, whose farming skills were quite advanced through training and whose farmlands had been improved. Consequently, their income from farming increased. From the range of income changes, it was found for $24.49 \%$ of the families with decreased incomes, their income decreased by more than $50 \%$; as for the families with increased incomes, $10.20 \%$ had their income increased by more than $100 \%$. The income structure of the migrant families also proved their income after migration decreased (Table 5). After migration, the percentage of low-income families increased, and the percentage of families with per capita net income below RMB 3000 yuan increased from $42.86 \%$ to $69.39 \%$ and the percentage of families with comparatively high per capita net income decreased to a certain extent, which reflected the impact of the ecological migration project on the income of farmer families.

The changes in life quality and assessment of the habitation in the new settlement were investigated.
Considering the comparatively unwelcome climatic conditions, serious salinization of farmlands, together with the incomplete infrastructures such as schools, hospitals and roads, the degree of satisfaction of farmer families was quite low, with $48.98 \%$ of the migrant families being unsatisfied with their habitation. Considering the changes in family income and living conditions, $42.86 \%$ of the migrant families believed their quality of life had declined (Fig. 8).

The migrant farmers' assessment of living conditions has significantly influenced their sense of belonging to the settlement. Consequently, improving the living condition and habitation in the settlement may enhance the enthusiasm of the migrants on their new life and smooth the ecological migration transition.

\subsection{Changes in the willingness to ecological mi- gration}

Farmer families were asked such questions as "Whether you would migrate voluntarily" and "If yes, whether you would be willing to migrate now" to investigate whether or not migrant farmer families

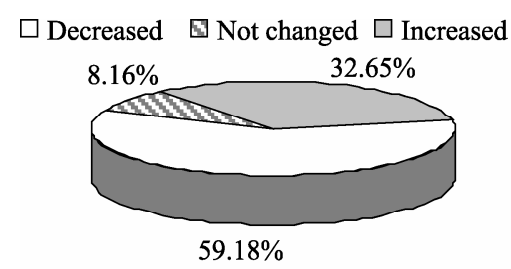

(a) Tendency of changes

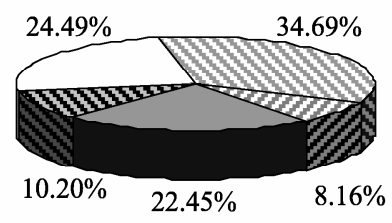

$\square$ Decreased by more than $50 \%$

종 Decreased by $0-50 \%$

$\square$ No changed

$\square$ Increased by $0-100 \%$

Increased by more than $100 \%$

(b) Extent of changes

Fig. 7 Changes of family income before and after ecological migration

Table 5 Changes of family annual per capita net income before and after ecological migration

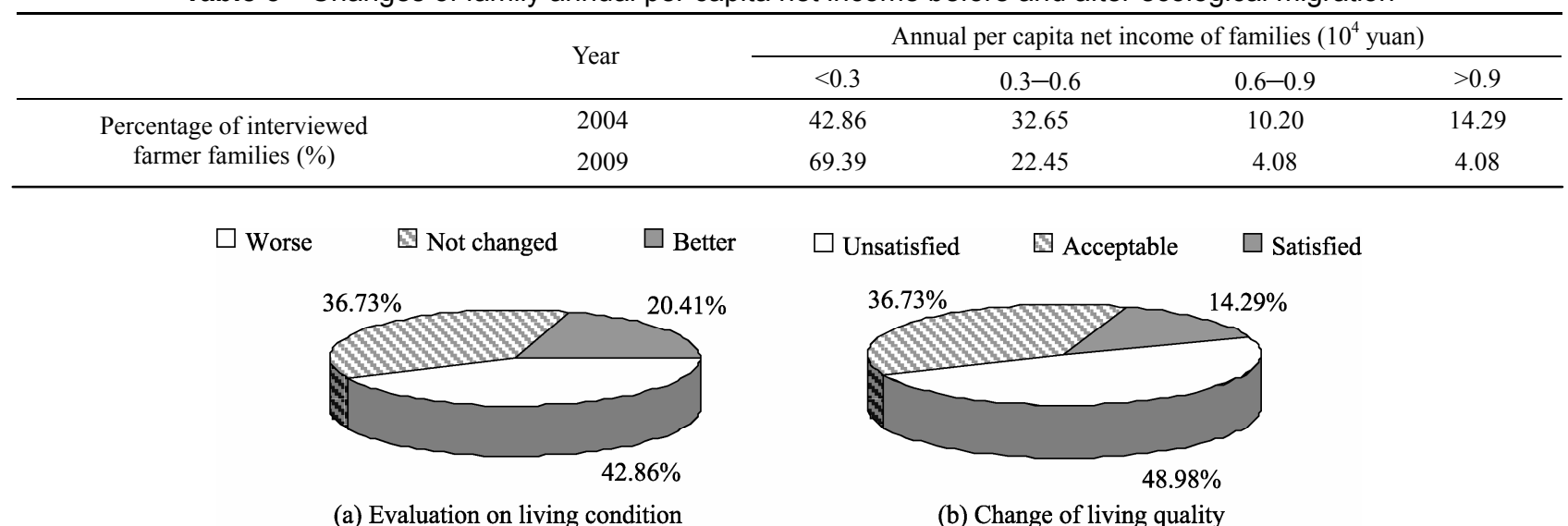

(a) Evaluation on living condition

(b) Change of living quality

Fig. 8 Changes of living conditions before and after ecological migration 
would be willing to make a supposed second migration. The aims of these questions were to find if farmer families had different attitudes before and after migration, and aimed to understand the change in attitudes towards migration. All involuntary migrants chose "no" when given the chance to make the decision to migrate again, and only $67.86 \%$ of the initial voluntaries were still willing to migrate. This shows that the ecological migration policy is not as successful as expected from the perspective of migrant farmer families. Quite a number of farmer migrants lost their confidence in the ecological migration project because their resettlement was not solved properly, their incomes decreased to some extent, and they were not satisfied with the living and production condition of the new settlement. The living condition and attitudes of migrated farmer families may have a tremendous influence on those who have not migrated yet. If their impressions were negative, it may hinder the advancement of migration projects.

\section{Conclusions and suggestions}

The types of farmer families and their awareness of the need for ecological and environmental protection have significant influences on the attitudes of farmers towards migration. Families with more members were generally less willing to migrate. Farmer families mainly deriving their income from farming and livestock raising were comparatively less willing to migrate than families who derived their income from business or tourism. The attitude of farmer families towards the project of returning farmland to forestry reflects in some way their awareness of the need for environmental protection, which was related to their willingness to migration. Ecological migration affected the major income sources and occupations of farmer families. After migration, the number of families whose major income source derived from farming with livestock raising increased, with the number of families living solely on livestock raising decreasing slightly and those living on tourism decreasing significantly.

With the implementation of the ecological migration project, the percentage of returning farmland to forestry increased significantly. Grassland degradation has been reduced to a certain degree due to decreased pressure on grasslands. After migration, the options for income sources for migrant families decreased and the amount of their incomes was also influenced negatively with more than half of migrant families' income decreased. Furthermore, the degree of satisfaction of migrants towards their habitation in the settlement was quite low. In other words, the changes in income and living conditions led to discontentment in migrant families, which might be a constraint to the implementation of future ecological migration project.

For the successful launch of an ecological migration project, the following suggestions are put forward:

(1) Propaganda should be enhanced to popularize the environmental consciousness and to improve the migrants' understanding to the ecological migration project, aiming to make subsequent migration projects successful as well.

(2) Investments on the migration project should be increased and salinized soil should be improved in order to improve the quality of farmlands. Drinking water for both human beings and animals and irrigation water should be provided in adequate quality and quantity. Infrastructures including roads, electric grids, schools, and hospitals should be enhanced to improve the life quality of migrants.

(3) Subsidies to aid living conditions and production and agricultural technological services should be provided by the local government. Training in farming techniques should be provided to improve the farming skills of migrant farmers in order to help their transfer from livestock raising to farming, thereby improving their adaptation to the new environment.

(4) Emphasis should be laid on the development of human resources. An effective way should be explored to reduce the dependence of migrant families on natural resources, particularly to reduce grazing pressure on grassland. Vocational training could be provided to migrants to encourage them to engage in part-time jobs, which would assist their vocational transfer from livestock raising to farming. Alternatively, preferential policies could be developed to encourage migrants to become self-employed, employed by local companies or become export laborers, through which, expansion of income sources and improvement of incomes would be possible. 


\section{Acknowledgements}

This study was funded by the National Natural Science Foundation of China (40801065) and the Dr. West-

\section{References}

Gai Z Y, Song W M, Chen J C. 2005. Ecological migration and its countermeasures in pasture areas. Journal of Beijing Forestry Unversity: Social Sciences, 4(3): 55-58.

Goujard B, Sakout A, Valeau V. 2005. Acoustic comfort on board ships: an evaluation based on a uestionnaire. Applied Acoustics, 66: 1063-1073.

Hong R, Li B, Chong J, et al. 2008. Application of rural household survey to returned cropland to forest or grassland project: a case study of Huangfuchuan watershed. Chinese Journal of Eco-Agriculture, 16(4): 995-999.

Li M X. 2007. Research on the influence of the ecological migration on the sustainable development of the grassland animal husbandry. MSc. Thesis. Hohhot: Inner Mongolia University.

Liu X Q,Wang L Q. 2010. Analysis of the effects of the ecological migration on the peasant housholds income and expenditure in Duolun country, Inner Mongolia. Forestry Economics, 3: 73-76.

Livestock Bureau of Fukang City. 2010. A research report about the economic development of pastoral and herdsmen settlement project. [2010-01-06]. http://www.fk.gov.cn/10059/10059/00004/2010/9266 6.htm.

Lu Q S, Zhao Z P. 2009. Eco-immigration policy for the degraded rangeland and response of herd families: a case study of Maduo county, the source region of Yellow River. Geographical Research, 28(1): 143-153 ern-funded projects of Chinese Academy of Sciences (XBBS 200803). The authors would like to thank XuNing QIAO, YuFang ZHANG and FuQiang XIA for revising the manuscript.

Meng X J, Liu Z H, Hu Z J. 2008. Preliminary study on the ecological restoration mechanism in arid area of northwestern China. Pratacultural Science, 25(3): 1-5.

Ren Y P, Lan J Y. 2008. The practice and model of grassland ecosystem replacement theory in Haven Lake Scenic Area of Tianshan Mountains. Grass-Feeding Livestock, 139(2): 47-49.

Tang H, Yang D G, Zhang X H, et al. 2011. Respond of farm household to eco-migration in Sangong River basin of Xinjiang. Progress in Geography, 30(4): 463-469.

Xu H G. 2001. Analysis on eco-migrate policy efficiency in grassland pressure relaxation. Territory \& Natural Resources Study, 4: 24-27.

Xu H L, Wang X P, Ye M, et al. 2007. The effect of eco-water transfer on the lower reaches of the Tarim River: analysis based on the results of the poll investigation. Geographical Research, 26(2): 246-254.

Ye M, Xu H L, Aihemti N, et al. 2007. Local residents response to ecological water re-inflowing into lower reaches of Tarim River. Journal of Desert Research, 27(1): 59-65.

Zhang Z L. 2005. Contracting for migration for the reason of zoological environment. Journal of Chongqing University: Natural Science, 28(8): 149-153.

Zhu Z A, Zhang X L. 2006. Theoretical critical value curve and driving force formation of ecological migration in the arid land. Chinese Science Bulletin, 51(Suppl.): 162-167. 